\title{
The relevance of the North-Sea Caspian Pattern (NCP) in explaining temperature variability in Europe and the Mediterranean
}

\author{
M. Brunetti ${ }^{1}$ and H. Kutiel ${ }^{2}$ \\ ${ }^{1}$ ISAC-CNR, Via Gobetti, 101, 40126 Bologna, Italy \\ ${ }^{2}$ Laboratory of Climatology, Department of Geography and Environmental Studies, University of Haifa, Haifa 31905, Israel
}

Received: 29 March 2011 - Revised: 11 July 2011 - Accepted: 26 August 2011 - Published: 27 October 2011

\begin{abstract}
The impact of the upper level $(500 \mathrm{hPa})$ teleconnection between the North-Sea and the Caspian (NCP) on the temperature and precipitation regimes in the Eastern Mediterranean (EM) have been studied and reported and an index (NCPI) that measures the normalized geopotential heights' differences between the two poles of this teleconnection has been defined.

In the present study, the impact of the NCP on the temperature regime over the entire European continent is presented. In particular, the correlation between temperature and the NCPI has been evaluated, on a monthly basis, over the entire Euro-Mediterranean domain for the 1948-2007 period. The results highlight a significant positive correlation in the north-western area of the domain and a significant negative correlation in the south-eastern one. These two poles were also highlighted by comparing the temperature anomalies associated with both phases of NCP.

The importance of this sort of NCP-induced temperature bi-pole in the context of temperature variability over Europe and the Mediterranean has been evaluated by applying a Principal Component Analysis to the temperature dataset. The results showed that the temperature bi-pole is associated with the second most important mode of temperature variability over the domain, but if the analysis is restricted to the months associated to NCP (+) and NCP (-), it becomes the first mode with $29.2 \%$ of associated variance.
\end{abstract}

\section{Introduction}

Atmospheric teleconnections on global and/or regional scales and their influence on temperature and/or precipitation regimes have been widely studied, especially during the

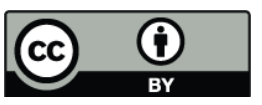

Correspondence to: $\mathrm{M}$. Brunetti

(m.brunetti@isac.cnr.it) last three decades (e.g., van Loon and Rogers, 1978; Rogers and van Loon, 1979; Wallace and Gutzler, 1981; Rogers, 1984; Barnston and Livezey, 1987; Lamb and Peppler, 1987; Glowienka-Hense, 1990; Rogers, 1990; Hurrell, 1995; Wallace, 2000; Stephenson et al., 2000; Ambaum et al., 2001; Wallace and Thompson, 2002; Ostermeier et al., 2003; PozoVazquez et al., 2005; Gamiz-Fortis et al., 2008a; GamizFortis et al., 2008b; Turkeş et al., 2009). The use of teleconnections in atmospheric research is very helpful as it reduces the dimensionality and the complexity of the atmosphere into one single (or few) modes and, therefore, is often used in statistical downscaling.

The most widely studied teleconnection affecting the Euro-Mediterranean climate is certainly the North Atlantic Oscillation (NAO) which primarily affects the rainfall regime in Western Europe and Northwestern Africa (e.g., van Loon and Rogers, 1978; Rogers and van Loon, 1979; Lamb and Peppler, 1987; Glowienka-Hense, 1990). Other teleconnections that affect parts of Europe are the Northern Annular Mode (NAM, e.g., Wallace, 2000; Wallace and Thompson, 2002; Ostermeier et al., 2003), Arctic Oscillation (AO, e.g., Ambaum et al., 2001; Higgins et al., 2002), Southern Europe North Atlantic (SENA, e.g., Kutiel and Kay, 1992), Scandinavian pattern (SCAND, e.g., Barnston and Livezey, 1987), East Atlantic (EA), East Atlantic Western Russia (EAWR, e.g., Barnston and Livezey, 1987; Krichak et al., 2002) just to mention a few. Most mentioned teleconnections are at the surface level. However, upper level circulation plays a major role on the temperature and precipitation regimes of a certain region (e.g., Kutiel and Kay, 1992). Kutiel et al., $2002 \mathrm{~b}$ suggested that an upper level $(500 \mathrm{hPa})$ teleconnection between the North Sea $\left(0^{\circ}-10^{\circ} \mathrm{E} / 55^{\circ} \mathrm{N}\right)$ and the Caspian $\left(50^{\circ}-60^{\circ} \mathrm{E} / 45^{\circ} \mathrm{N}, \mathrm{NCP}\right.$, hereafter) may have a crucial impact on the temperature and precipitation regimes in the Eastern Mediterranean (EM).

Kutiel and Benaroch (2002a) defined an index which calculated the normalized geopotential height differences

Published by Copernicus Publications on behalf of the European Geosciences Union. 

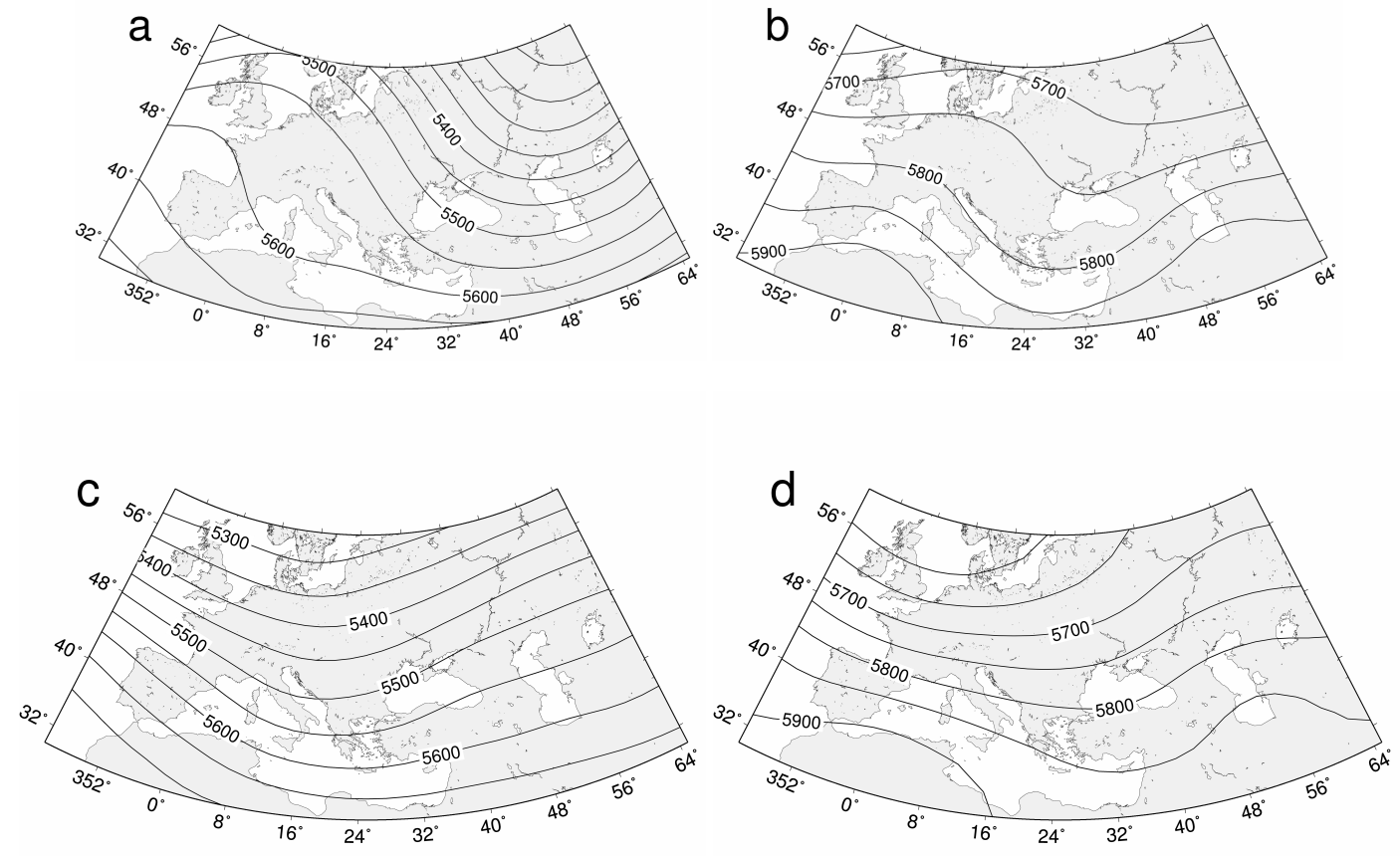

Fig. 1. Mean absolute geopotential heights (GPH) during NCP (+) in January (a); NCP (+) in July (b); NCP (-) in January (c) and NCP (-) in July (d).

between these two poles. This index served to analyse the impact of the NCP on the precipitation, temperature and SST regimes in the EM (Kutiel et al., 2002b; Hatzaki et al., 2007; Kostopoulou and Jones, 2007; Tatli, 2007), in the Balkans (Brown and Petkova, 2007), over the Black Sea (Kazmin and Zatsepin, 2007), in Turkey (Kutiel et al., 2005; Turkeş et al., 2009), in Israel (Feldstein and Dayan, 2008), in Egypt (Hasanean, 2004) and in Iran (Ghasemi and Khalili, 2008a,b), just to mention a few.

All cited studies were focused on the EM and its surroundings as this region was the initial focal point of the $\mathrm{NCP}(\mathrm{Ku}-$ tiel and Benaroch, 2002a; Kutiel et al., 2002b). However, as the poles of the NCP are located further north, it is expected that its impact will spread out over a much wider region and may affect even the entire European continent and the whole Mediterranean basin.

The regional circulation, together with local characteristics such as topography, sea-land interactions, orientation, slope, etc., affects both the temperature and precipitation regimes in a certain location. However, while temperature anomalies are characterised by a higher spatial coherence, being mostly affected by large scale circulation, precipitation is affected a great deal by local conditions and characterised by a shorter decorrelation distance (Auer et al., 2007; Brunetti et al., 2006). Kutiel et al. (2002b) illustrated how, even in a limited region such as the EM, the NCP has a similar impact on the temperature anomaly distribution of the entire region despite its physiographic variability; above normal temperatures during the negative phase of the NCP and below normal during its positive phase. However, the impact of the NCP on the rainfall regime of that region, varies from one place to another depending on the body of water (Mediterranean or Atlantic) affecting the area under consideration. Therefore, it is expected that over the entire European continent and the Mediterranean basin, with all its topographic variety, latitudinal extent maritime or continental locations, it will be difficult to point out the impact of the $\mathrm{NCP}$ on the rainfall regime, but possible to detect its impact on the temperature regime.

The purposes of the present study are, therefore, to evaluate the temperature anomalies associated with both phases of the NCP, their areal extent within the European continent, the Mediterranean basin and the Middle East (ME). To achieve this goal, the geopotential heights' departures in each of the phases will be calculated and the anomalous circulation related to them will be evaluated.

\section{Data and methods}

Daily gridded geopotential heights at the $500 \mathrm{hPa}$ level (Z500), from NCEP/NCAR re-analysis (Kalnay et al., 2006) with a $2.5^{\circ} \times 2.5^{\circ}$ resolution in the region delimited by $15.0^{\circ} \mathrm{W}-65.0^{\circ} \mathrm{E}$ longitude and $30.0^{\circ} \mathrm{N}-60.0^{\circ} \mathrm{N}$ latitude 

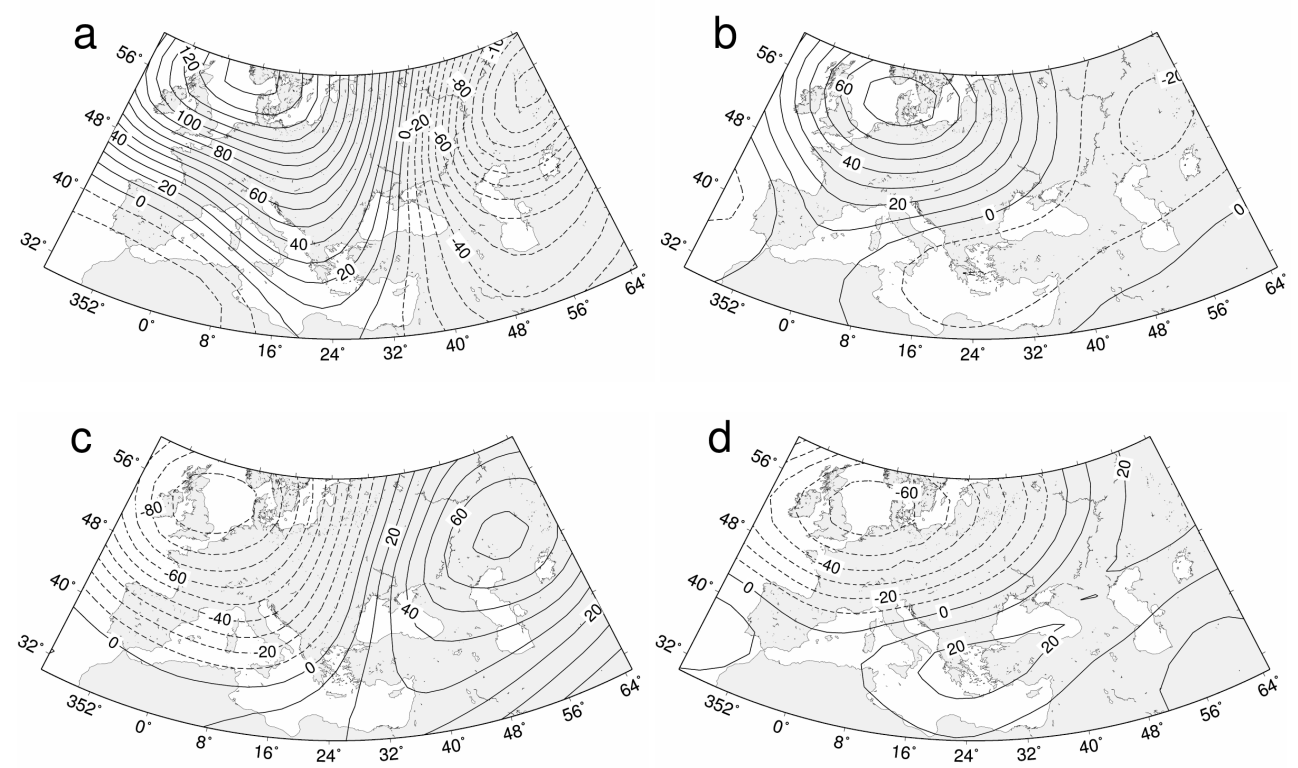

Fig. 2. Same as Fig. 1, but for mean geopotential heights departures.

were used for the period 1948-2007 converted into monthly averages.

For the same period, the $5.0^{\circ} \times 5.0^{\circ}$ resolution gridded global monthly temperature anomalies dataset (relative to the 1961-1990 period) of the Climate Research Unit (Brohan et al., 2006) was used to study temperature anomalies in relation to the NCP.

The NCP index (NCPI) and the positive and negative phases were calculated and defined for every month of the analysis period according to the formula proposed by $\mathrm{Ku}-$ tiel and Benaroch (2002a) with two slight modifications: The geopotential height of each pole was calculated at a $2.5^{\circ} \times 2.5^{\circ}$ resolution instead of $10.0^{\circ} \times 10.0^{\circ}$ as in Kutiel and Benaroch (2002a).

$X_{i}=\overline{Z_{i}\left(0.0^{\circ}, 2.5^{\circ}, 5.0^{\circ}, 7.5^{\circ}, 10.0^{\circ} \mathrm{E} ; 55.0^{\circ} \mathrm{N}\right)}$

$-\overline{Z_{i}\left(50.0^{\circ}, 52.5^{\circ}, 55.0^{\circ}, 57.5^{\circ}, 60.0^{\circ} \mathrm{E} ; 45.0^{\circ} \mathrm{N}\right)}$

(where $i$ indicates the time step) and then these values were standardized as follows:

$\mathrm{NCPI}_{i}=\frac{X_{i}-\bar{X}}{\sigma}$

The negative phase NCP $(-)$ and the positive phase NCP (+) were defined when:

$\mathrm{NCPI}_{i}<-1.0$ and $\mathrm{NCPI}_{i}>1.0$, respectively (instead of \pm 0.5 standard deviation as originally defined, to restrict the analysis to the most severe cases). The total number of cases of NCP (-) and NCP (+) are 243 over a total of 720 monthly values, corresponding to about $33 \%$.

All the following analyses are performed on a monthly basis, even when seasonal results are presented (the analysis is restricted to the months belonging to the season in question).

\section{Results and discussion}

\subsection{Z500 fields analysis and Z500 fields departures}

To understand which is the atmospheric circulation associated to $\mathrm{NCP}(+)$ and $\mathrm{NCP}(-)$ and then to interpret the corresponding temperature anomaly fields, the months characterised by $\mathrm{NCP}(+)$ and $\mathrm{NCP}(-)$ have been selected and the associated Z500 fields (both in absolute terms and as anomalies) have been averaged and plotted (Figs. 1 and 2).

During the negative phase, NCP (-), the Z500 is lower over the North Sea and higher over the Caspian (Fig. 2c, d) and vice versa during NCP (+) (Fig. 2a, b). Therefore, the anomaly circulation related to $\mathrm{NCP}(-)$ is counterclockwise around the North Sea and clockwise around the Caspian resulting in an increased southerly (or southwesterly) circulation in all the region between the North Sea and the Caspian. The opposite is true during the NCP (+), when the same region is under an increased northerly (or northeasterly) circulation (Fig. 2a, b). However, the regions beyond these two poles, i.e., west of the North Sea and east of the Caspian are under opposite circulation conditions. In these regions the anomaly circulation is mainly northerly during NCP $(-)$ and mainly southerly during NCP (+). Therefore, one should expect that during the same phase of the NCP, under the same anomalous conditions, the impact on the temperature will be opposite in different parts of the study area.

It should be made clear that the anomaly circulation refers to the change of the circulation and does not imply that this is the real circulation. For example, a northerly anomaly circulation may be due to an increase in northerly circulation or to a decrease in southerly circulation (as it is clear by comparing 

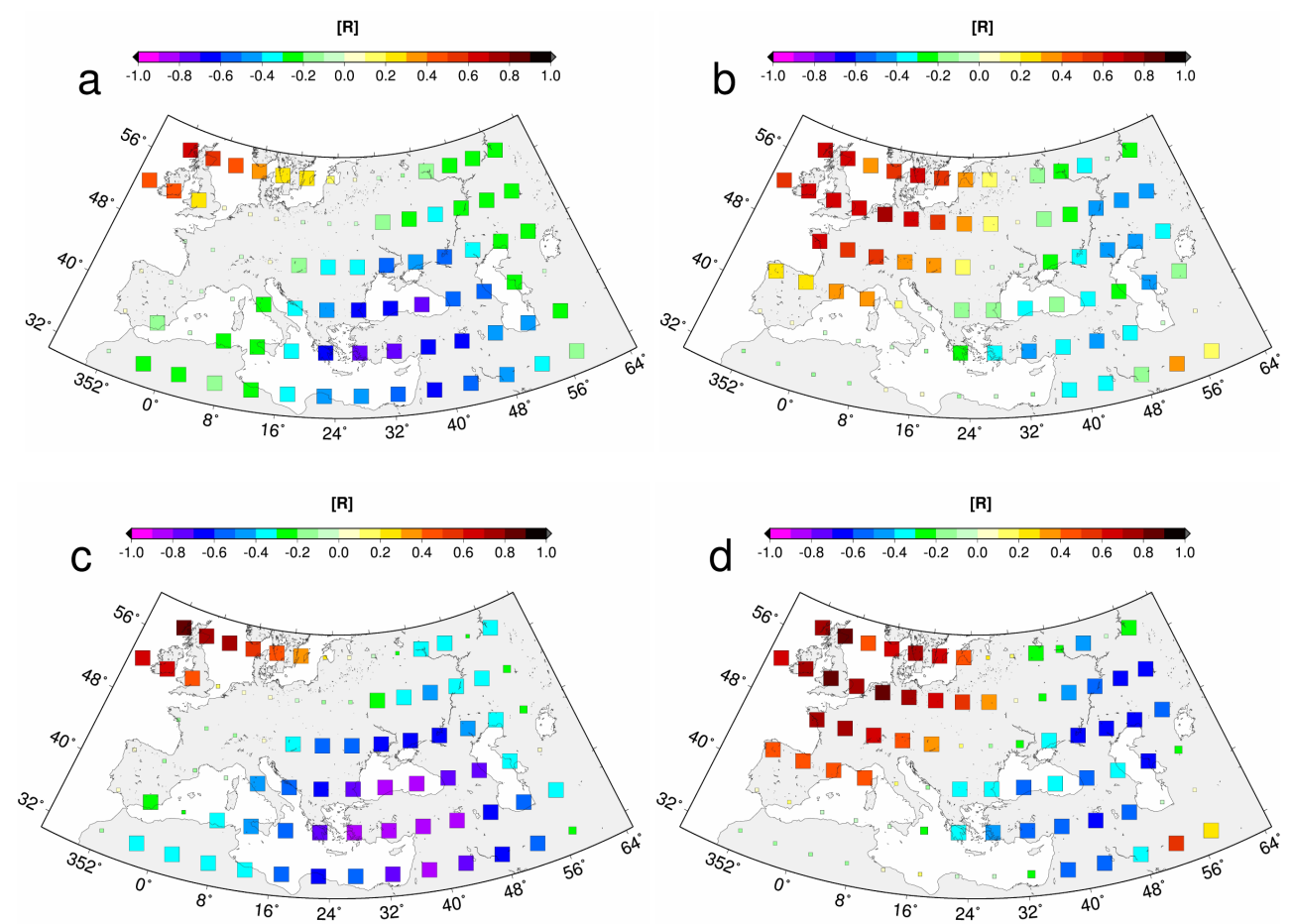

Fig. 3. Correlation coefficients between temperature and NCPI for all cases, in December-January-February (a); in June-July-August (b); only for $|\mathrm{NCPI}|>1.0$, in December-January-February (c) and in June-July-August (d). Squares' sizes are relative to the significance level (large squares, $p<0.01$; medium squares, $p<0.05$; small squares, $p>0.1$ ).

Fig. 1a-d with Fig. 2a-d). In both cases, the impact on temperature departure is expected to be the same. As one of the goals of the present study is to analyse how changes in circulations relate to the phases of the NCP influence temperature departures and not the temperature themselves, the use of anomalous circulation is the most appropriate approach.

\subsection{Temperature-NCPI correlation}

The correlation (Pearson correlation) between temperature and the NCPI has been evaluated, on a monthly basis, over the whole Euro-Mediterranean domain for the 1948-2007 period. Monthly data anomalies of DJF were analysed together for the winter and of JJA for the summer, to improve the robustness of the statistical sample of data and avoid changes due to the insufficient number of cases, that may affect correlation when considering only the values associated with NCP (+) and NCP (-).

The results highlight a significant positive correlation in the north-western area of the domain and a significant negative correlation in the south-eastern one (Fig. 3).

Interesting differences between summer and winter months are clearly evident by comparing Fig. 3a, b. In winter (correlation considering DJF is shown in Fig. 3a) there is a large area, covering the whole eastern Mediterranean basin, the Black Sea, the Caspian Sea and northward to the Volga basin, characterised by negative correlation, while the pos- itive correlation area is confined to a few grid cells in the far north-western part of the domain. In summer (i.e., considering JJA in the correlation analysis), on the contrary, the negatively correlated area is limited to the eastern part of the box: part of Greece, Turkey, Caspian sea and Volga basin, while the positively correlated ones are extend southward to the northern coast of the Mediterranean basin (Fig. 3b), i.e., there is a clear shift towards the south-east of the edge between positive and negative correlated areas.

Autumn and spring (figures not shown) present similar patterns of transition between the most extreme cases of winter and summer. If we consider only the monthly values corresponding to $\mathrm{NCP}(+)$ and $\mathrm{NCP}(-)$ conditions, the results are even clearer with an increase in the correlation (Fig. 3c, d).

\subsection{Temperature anomalies associated with NCP (+) and NCP (-)}

On the light of these results, we would expect temperature anomalies of an opposite sign in the two areas characterised by opposite correlation and a change from positive to negative (and vice versa) for those months with $\mathrm{NCP}(+)$ and those with NCP (-). In fact, if we plot on a map the mean temperature anomaly field obtained averaging the temperature fields corresponding to the months associated to NCP (+) and that obtained averaging the temperature fields corresponding to 

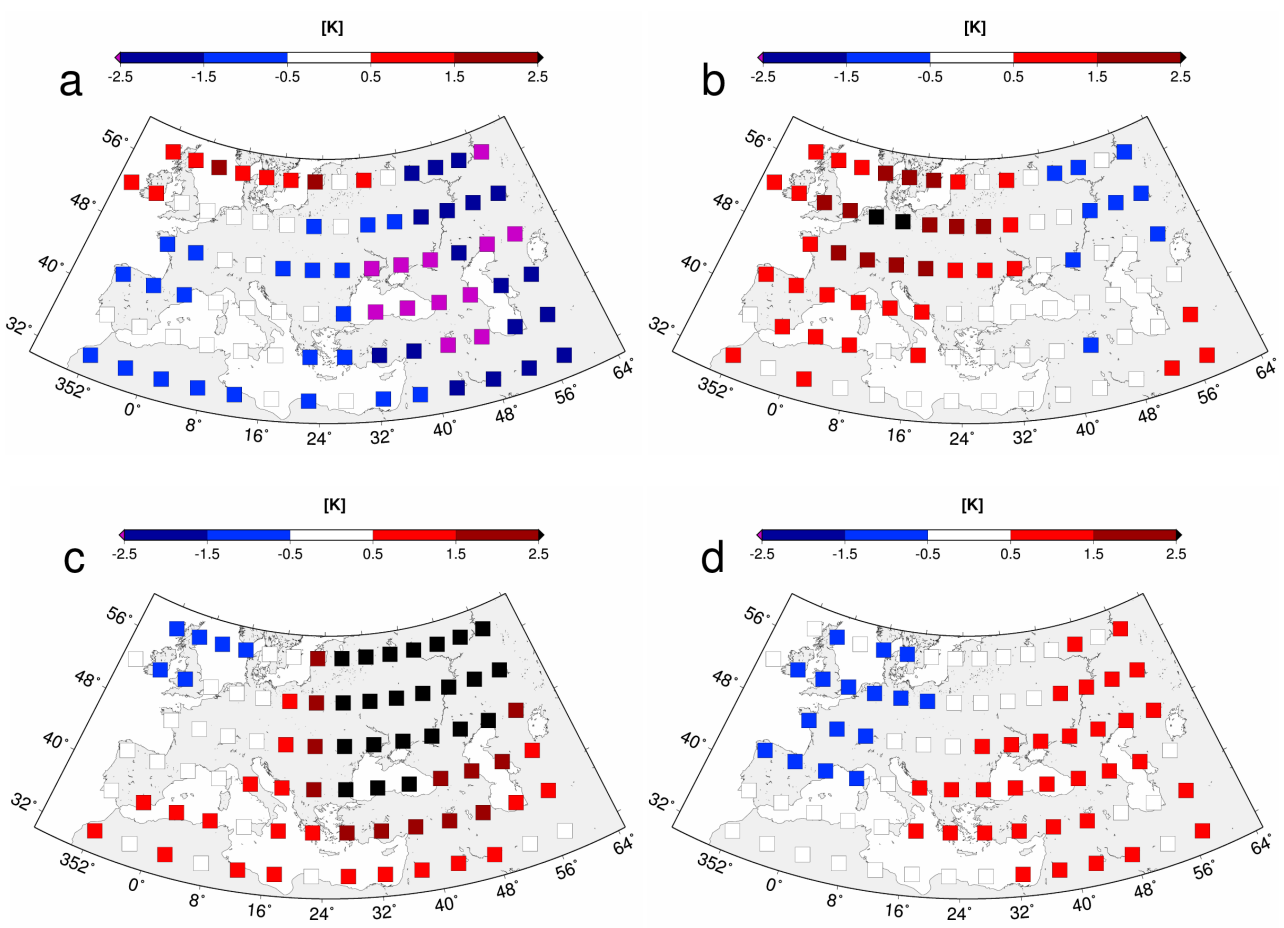

Fig. 4. Same as Fig. 2, but for mean temperature departures.

the months associated to NCP (-), the change from positive to negative anomaly and vice versa is clear (Fig. 4).

The origin of these anomalies are easily understandable comparing Fig. 4 with Fig. 2. In January, as an example, during NCP (+) conditions, there is a northerly anomaly circulation in the region between the North Sea and the Caspian, crossing over the Black Sea and down up to Turkey (Fig. 2a), in the same month (January during NCP (+) conditions) temperature anomalies are negative over the same area, with the strongest negative anomalies over the Black Sea (Fig. 4a). By the other end, in the same month (January) but during NCP (-) conditions, the anomaly circulation is southerly (Fig. 2c) over the same area (indicating a stronger southerly component or a weaker northerly one in the absolute circulation) and this is the cause of a strong positive temperature anomaly (Fig. 4c).

Over the British Isles and the North Sea, the anomaly circulation in both phases of the NCP, is opposite to that over the Black Sea, Turkey and the ME (Fig. 2a, c) and, therefore, temperature departures are accordingly opposite, i.e., above normal during NCP $(+)$ and below normal during NCP (-) (Fig. 4a, c).

\subsection{Principal Component Analysis}

To understand the importance of this bipolar temperature pattern in the context of temperature variability over the Euro-Mediterranean region, a Principal Component Analysis
(PCA) has been applied to the temperature anomalies dataset on the study domain to verify if it is represented by one of the leading Empirical Orthogonal Functions (EOFs) and, if yes, its associated fraction of variance.

Applying a PCA to the monthly temperature anomalies dataset, the major part of the variance (up to $61.9 \%$ ) is explained by the first 3 components. As it can be seen from Fig. 5, the first component that takes into account $26.7 \%$ of the total variance is representative of temperature variability over Europe as a whole, the second and third components represent a north-west/south-east and a north-east/south-west bipolar pattern, respectively, the former explaining $20.5 \%$ of the total variance and the latter $14.7 \%$.

The association of the second EOF with the NCP is immediately clear, being the two areas of the dipole those characterised by opposite correlation with respect to the NCPI and opposite temperature anomalies in association to NCP (+) and NCP (-) conditions.

In fact, if we restrict the PCA only to the monthly temperature anomalies associated to $\mathrm{NCP}(+)$ and $\mathrm{NCP}(-)$, we obtain the same three temperature patters, but differently ranked as it is evident from Fig. 6. Now, the north-west/south-east pattern (i.e., that associated to NCP) is the most important and explains $29.2 \%$ of the total variance, while the second one (corresponding to the first EOF in the previous analysis) explains only $21.3 \%$ of the total variance. Together with the third EOF (15.5\%), the explained variance by these three components sums to $66 \%$. 

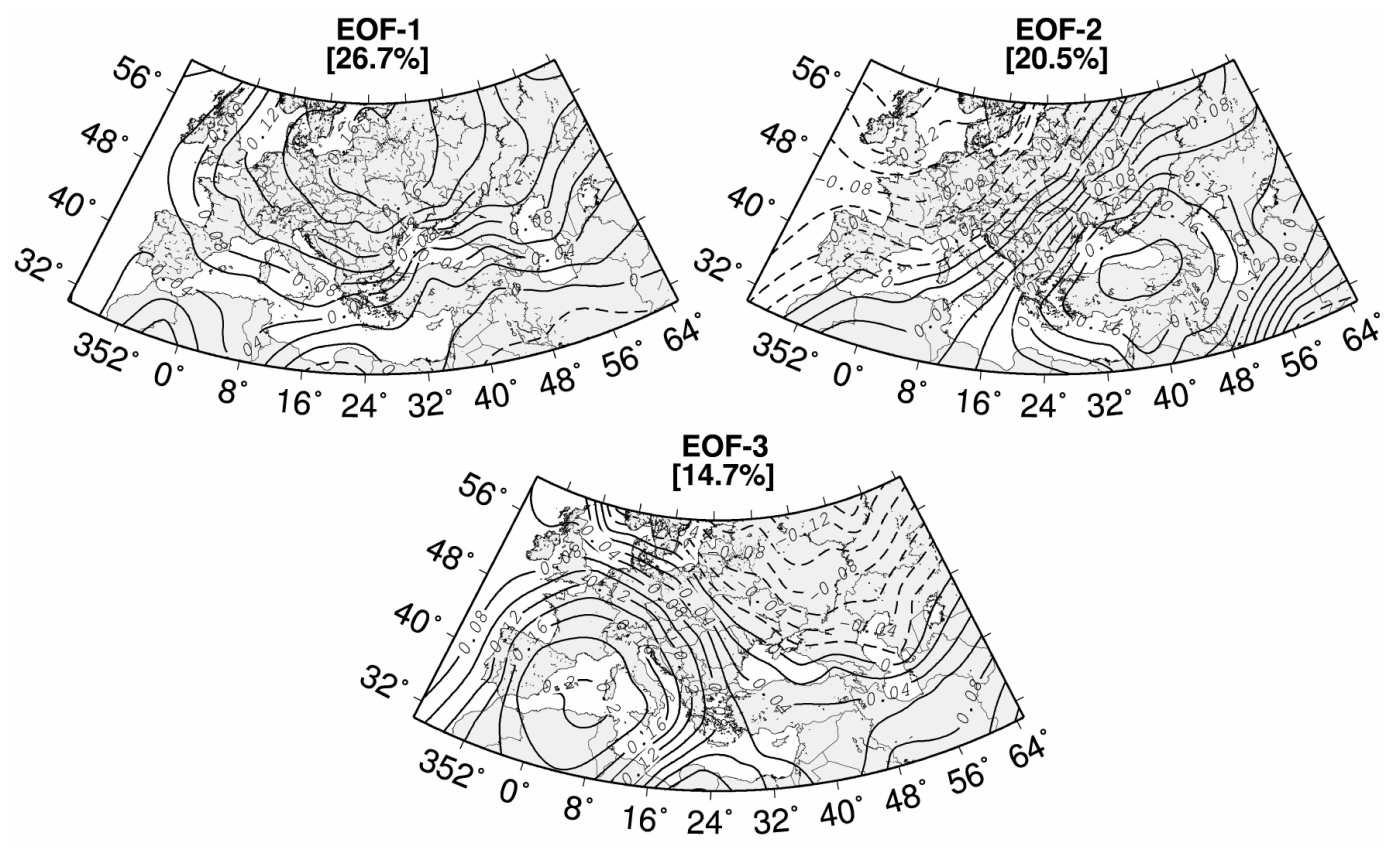

Fig. 5. The three obtained EOF and their explained variance, for all cases.
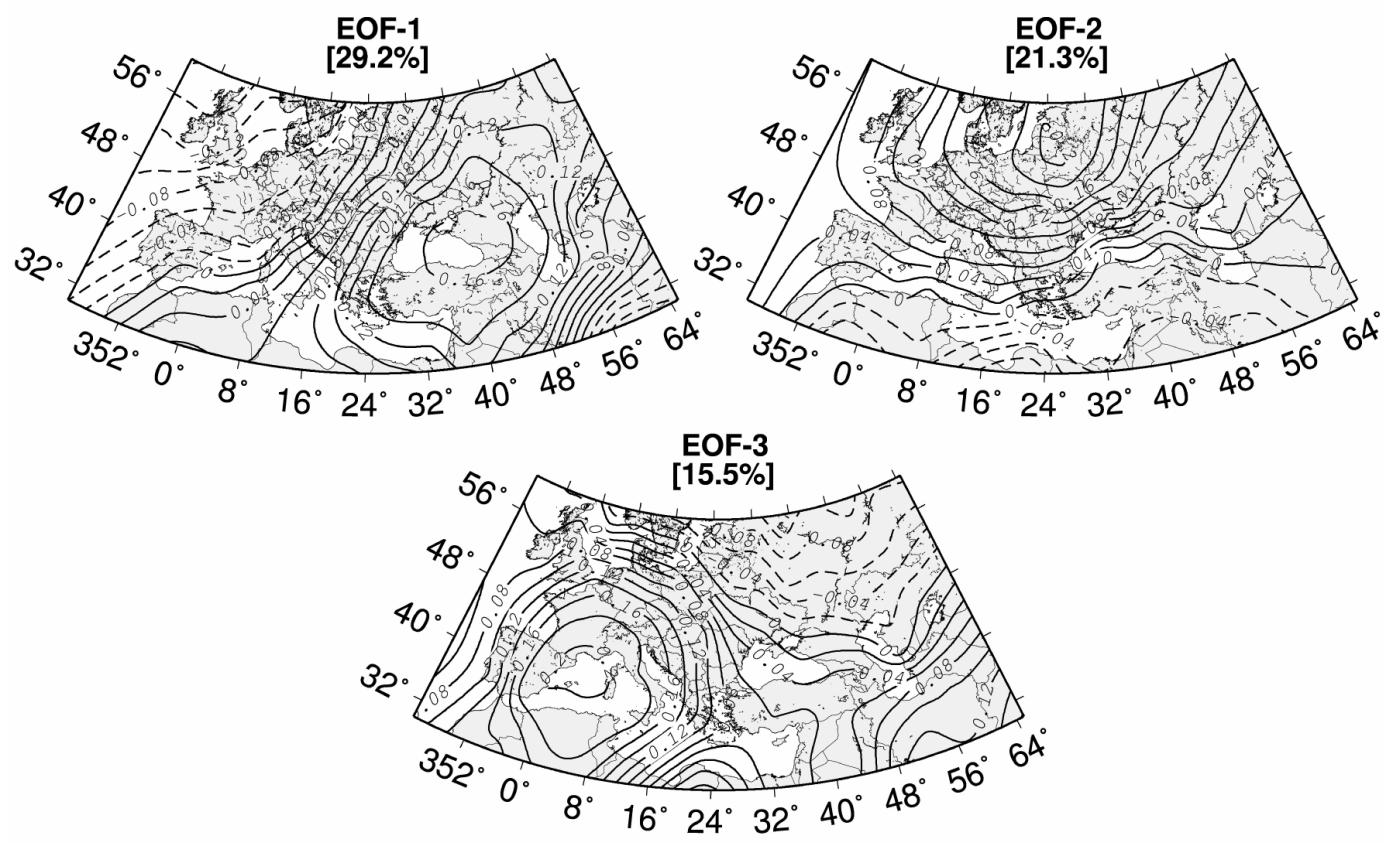

Fig. 6. Same as Fig. 5, but only for $|\mathrm{NCPI}|>1.0$. 
This indicates that NCP is representative of an atmospheric circulation linked to one of the most relevant modes of temperature variability, affecting in an opposite way the two macro-areas highlighted in Fig. 2.

\section{Conclusions}

The presented results reveal the major role of the upper level circulation on the temperature distribution over the European continent and the Mediterranean basin. The NCP represents one of the most important modes of this circulation as it discriminates between meridional (either from the north or from the south) and zonal circulations (either from the east or from the west) in its positive and negative phase, respectively. In the present study, this role was proven again, but this time over a much wider region than in previous studies in which the role of the NCP was studied, proving the leading role of the NCP at the Euro-Mediterranean scale.

The specific conclusions of the present study may be summarized as follows:

- During NCP (+), the circulation over the study area tends to be more meridional, whereas during NCP (-) more zonal both in winter and in summer.

- The anomaly circulation during NCP (+) in winter, is mainly northerly over major parts of Eastern Europe, the Black and the Caspian seas and the ME, causing a considerable decrease in temperatures compared to the normal conditions. The opposite is true during NCP (-). On the other hand, over the British Isles and Southern Scandinavia the impact of the NCP in winter, is opposite, i.e., warmer conditions during $\mathrm{NCP}(+)$ and cooler during $\mathrm{NCP}(-)$, but to a lesser extent.

- In summer, the impact of the NCP on the temperatures over the ME and the Caspian region is less pronounced compared to the winter. However, there is a major impact on the temperatures over Western and Central Europe and Southern Scandinavia. During NCP (+), temperatures over these regions are considerably higher than normal and below normal during NCP $(-)$.

- PCA performed on the temperature dataset of all cases over the study region, reflected the bipolar distribution as the second component explaining over $20 \%$ of the total variability. When the PCA was performed only on cases when $|\mathrm{NCPI}|>1.0$, this bipolar distribution turned to be the first component explaining almost $30 \%$ of the total variance.

The presented results illustrate again the benefits of using indices in representing the major components of the atmospheric circulation as a useful research tool, by reducing the dimensionality and the complexity of the atmosphere into one single figure.
Acknowledgements. We would like to thank the Climate Research Unit of the University of East Anglia (UK) for providing the temperature data, and NCEP/NCAR for the reanalysis. This study has been carried out in the framework of the EU project ECLISE (ID 265240) and of the CMCC/ISAC-CNR agreement 'Validazione e downscaling di scenari prodotti con modelli climatici attraverso l'utilizzo di una griglia di variabili meteorologiche ad altissima risoluzione'.

Edited by: K. Lagouvardos

Reviewed by: K. Nicolaides and two other anonymous referees

\section{References}

Ambaum, M. H. P., Hoskins, B. J., and Stephenson, D. B.: Arctic Oscillation or North Atlantic Oscillation?, J. Climate, 14, 34953507, 2001.

Auer, I., Matulla, C., Boehm, R., Ungersboeck, M., Maugeri, M., Nanni, T., and Pastorelli, R.: Sensitivity of Frost Occurence to Temperature Variablity in the European Alps, Int. J. Climatol., 25, 1749-1766, 2005.

Barnston, A. G. and Livezey, R. E.: Classification, seasonality and persistence of low-frequency atmospheric circulation patterns, Mon. Weather Rev., 115, 1083-1126, 1987.

Brohan, P., Kennedy, J. J., Harris, I., Tett, S. F. B., and Jones, P. D.: Uncertainty estimates in regional and global observed temperature changes: a new dataset from 1850, J. Geophys. Res., 111, D12106, doi:10.1029/2005JD006548, 2006.

Brown, R. D. and Petkova, N.: Snow cover variability in Bulgarian mountainous regions, 1931-2000, Int. J. Climatol., 27, 12151229, 2007.

Brunetti, M., Maugeri, M., Monti, F., and Nanni, T.: Temperature and precipitation variability in Italy in the last two centuries from homogenized instrumental time series, Int. J. Climatol., 26, 345381, 2006.

Feldstein, S. B. and Dayan, U.: Circumglobal teleconnections and wave packets associated with Israeli winter precipitation, Q. J. Roy. Meteor. Soc., 134, 455-467, 2008.

Gamiz-Fortis, S., Pozo-Vazquez, D., Trigo, R. M. and Castro-Diez, Y.: Quantifying the predictability of winter river flow in Iberia. Part I: Interannual predictability, J. Climate, 21, 2484-2502, 2008a.

Gamiz-Fortis, S., Pozo-Vazquez, D., Trigo, R. M., and CastroDiez, Y.: Quantifying the predictability of winter river flow in Iberia. Part II: Seasonal predictability, J. Climate, 21, 25032518, 2008b.

Ghasemi, A. R. and Khalili, D.: The effect of the North Sea-Caspian pattern $(\mathrm{NCP})$ on winter temperatures in Iran, Theor. Appl. Climatol., 92, 59-74, 2008a

Ghasemi, A. R. and Khalili, D.: The association between regional and global atmospheric patterns and winter precipitation in Iran, Atmos. Res., 88, 116-133, 2008b.

Glowienka-Hense, R.: The North Atlantic Oscillation in the Atlantic-European SLP, Tellus, 42A, 497-507, 1990.

Hasanean, H. M.: Wintertime surface temperature in Egypt in relation to the associated atmospheric circulation, Int. J. Climatol., 24, 985-999, 2004.

Hatzaki, M., Flocas, H. A., Asimakopoulos, D. N., and Maheras, P.: The eastern Mediterranean teleconnection pattern: identification 
and definition. Int. J. Climatol., 27, 727-737, 2007.

Higgins, R. W., Leetmaa, A., and Kousky, V. E.: Relationships between climate variability and winter temperature extremes in the United States, J. Climate, 15, 1555-1572, 2002.

Hurrell, J. W.: Decadal trends in the North Atlantic Oscillation: Regional temperatures and precipitation, Science, 269, 676-679, 1995.

Kazmin, A. S. and Zatsepin, A. G.: Long-term variability of surface temperature in the Black Sea, and its connection with the largescale atmospheric forcing, J. Marine Syst., 68 293-301, 2007.

Kalnay, E., Kanamitsu, M., Kistler, R., Collins, W., Deaven, D., Gandin, L., Iredell, M., Saha, S., White, G., Woollen, J., Zhu, Y., Chelliah, M., Ebisuzaki, W., Higgins, W., Janowiak, J., Mo, K. C., Ropelewski, C., Wang, J., Leetmaa, A., Reynolds, R., Jenne, R., and Joseph, D.: The NCEP/NCAR 40-year reanalysis project, B. Am. Meteorol. Soc., 77, 437-471, 2006.

Kostopoulou, E. and Jones, P. D.: Comprehensive analysis of the climate variability in the eastern Mediterranean. Part II: relationships between atmospheric circulation patterns and surface climatic elements, Int. J. Climatol., 27, 1351-1371, 2007.

Krichak S. O., Kishcha, P.,and Alpert, P.: Decadal trends of main Eurasian oscillations and the Eastern Mediterranean precipitation, Theor. Appl. Climatol., 72, 209-220, 2002.

Kutiel, H. and Benaroch, Y.: North Sea-Caspian Pattern (NCP) an upper level atmospheric teleconnection affecting the Eastern Mediterranean: Identification and definition, Theor. Appl. Climatol., 71, 17-28, 2002a.

Kutiel, H., Maheras, P., Turkeş, M., and Paz, S.: North Sea Caspian Pattern (NCP) - an upper level atmospheric teleconnection affecting the eastern Mediterranean - implications on the regional climate, Theor. Appl. Climatol., 72, 173-192, 2002b.

Kutiel, H. and Kay, P. A.: Recent variations in the $700 \mathrm{hPa}$ geopotential heights in summer over Europe and the Middle East, and their influence on other meteorological factors, Theor. Appl. Climatol., 46, 99-108, 1992.

Kutiel, H. and Turkeş, M.: New Evidence for the role of the North Sea Caspian Pattern on the temperature and precipitation regimes in continental central Turkey, 87A, 501-513, 2005.

Lamb, P. J. and Peppler, R. A.: North Atlantic Oscillation: Concepts and an application, B. Am. Meteorol. Soc., 68, 1218-1225, 1987.
Ostermeier, G. M.and Wallace, J. M.: Trends in the North Atlantic Oscillation Northern Hemisphere Annular Mode during the Twentieth Century, J. Climate, 16, 336-341, 2003.

Pozo-Vazquez, D., Gamiz-Fortis, S.R., Tovar-Pescador, J., EstebanParra, M. J., and Castro-Diez, Y.: El Nino Southern oscillation events and associated European winter precipitation anomalies, Int. J. Climatol., 25, 17-31, 2005.

Rogers, J. C.: The association between the North Atlantic Oscillation and the Southern Oscillation in the Northern Hemisphere, Mon. Weather Rev., 112, 1999-2015, 1984.

Rogers, J. C.: Patterns of low-frequency monthly sea level pressure variability (1899-1986) and associated wave cyclone frequencies, J. Climate, 3, 1364-1379, 1990.

Rogers, J. C. and van Loon, H.: The seesaw in winter temperature between Greenland and northern Europe. Part II: Some oceanic and atmospheric effects in middle and high altitudes, Mon. Weather Rev., 107, 1364-1379, 1979.

Stephenson, D. B., Pavan, V., and Bojariu, R.: Is the North Atlantic Oscillation a random walk?, Int. J. Climatol., 20, 1-18, 2000.

Tatli, H.: Synchronization between the North Sea-Caspian pattern (NCP) and surface air temperatures in NCEP, Int. J. Climatol., 27, 1171-1187, 2007.

Turkeş, M., Koc, T., and Saris, F.: Spatiotemporal variability of precipitation total series over Turkey, Int. J. Climatol., 29, 10561074, 2009.

van Loon, H. and Rogers, J. C.: The seesaw in winter temperature between Greenland and northern Europe. Part I: General description, Mon. Weather Rev., 106, 296-310, 1978.

Wallace, J. and Gutzler, D.: Teleconnections in the geopotential height field during the Northern Hemisphere winter, Mon. Weather Rev., 109, 784-812, 1981.

Wallace, J. M.: North Atlantic Oscillation/Annular Mode: Two Paradigms One Phenomenon, Q. J. Roy. Meteorol. Soc., 126 , 791-805, 2000.

Wallace, J. M. and Thompson, D. W. J.: The Pacific Center of Action of the Northern Hemisphere Annular Mode: Real or Artifact?, J. Climate, 15, 1987-1991, 2002. 